\title{
Projeto Sopa de Letrinhas
}

\author{
Regina Célia de Jesus D. Santos ${ }^{1}$, Lilian T. Carvalho ${ }^{1}$ \\ ${ }^{1}$ Secretaria Municipal de Educação de Cabo Frio - Departamento de Formação \\ Continuada - Centro de Estudos de Educação Natália Caldonazzi - NTM Cabo Frio \\ Cabo Frio - RJ - Brasil \\ reginacjds@gmail.com, liantcarvalho@yahoo.com.br
}

\begin{abstract}
This summarized article describes one of the actions of the Secretaria Municipal de Educação do Município de Cabo Frio to aid in the Literacy process of students of the Municipal Schools Rede Municipal de Educação de Cabo Frio, using technological resources, especially animation.
\end{abstract}

Resumo. Este artigo resumido descreve uma das ações da Secretaria Municipal de Educação do Município de Cabo Frio para o auxílio no processo de Alfabetização e Letramento dos alunos da Rede Municipal de Educação de Cabo Frio, utilizando recursos tecnológicos, em especial a animação.

\section{Introdução}

"A era da informação requer profunda revisão do sistema educativo. Sua tarefa é formar as novas gerações, respeitando sua natureza e tendo consciência de suas necessidades, que estão mudando, e a escola não pode ignorar isso.” Lollini, 1985

Segundo Fernandes (1991), a aprendizagem “...É um processo pessoal, dependendo do envolvimento de cada um, de seu esforço e de sua capacidade, aprendendo-se aos poucos e cada um de acordo com seu ritmo próprio". in Stampa, 2009

Cada indivíduo aprende a seu tempo e modo, por ser dotado de características individuais, que se evidenciam de acordo com os estímulos que recebe em seu contexto sociocultural. Dessa forma, o meio no qual a criança está inserida é determinante para a aprendizagem. No caso específico da Alfabetização, o elemento lúdico, que é acessível a qualquer classe social, se constitui um estímulo positivo, pois alimenta a imaginação e a criatividade, que são ferramentas essenciais para o desenvolvimento da linguagem oral e escrita.

A importância do lúdico aliada ao crescente interesse das crianças nessa fase de desenvolvimento pelas tecnologias disponíveis motivaram o Departamento de Formação Continuada mediante iniciativa do Centro de Estudos de Educação Natália Caldonazzi e seu Núcleo de Tecnologia Educacional Municipal a desenvolver o Projeto Sopa de Letrinhas, cuja proposta é unir o lúdico do desenho animado com os conceitos, princípios e conteúdos inerentes à Alfabetização.

A SEME Cabo Frio entende a Alfabetização numa perspectiva sócio interacionista e adota a Proposta Metodológica Analítica. De acordo com o REDE ALFA, 2006 (Referencial de Alfabetização do Município), "o indivíduo aprenderá a ler $e$ a escrever participando de situações e práticas sociais que propiciem esse aprendizado". E, deve-se iniciar "o processo de alfabetização partindo de unidades 
significativas da língua,...." onde "A criança deverá primeiro ser capaz de perceber globalmente cada elemento significativo e, só depois, sua atenção poderá ser conduzida para as unidades".

A Proposta Metodológica Analítica entende o processo de alfabetização partindo de unidades significativas da língua, ou seja, de palavras, frases, parágrafos ou textos. Estimula-se a compreensão do elemento significativo, que precisa estar relacionado ao contexto sociocultural do aluno, para, a partir dele, compreender as unidades menores. Nesta proposta, os textos se segmentam em palavras, as palavras em sílabas e as sílabas em fonemas. Estes fonemas são comutados dando origem a novas palavras.

A primeira animação do Projeto Sopa de Letrinhas retrata uma problemática vivenciada por muitos alunos, que, embora conheçam as letras do alfabeto, demonstram dificuldades em relacioná-las a seus respectivos sons. Conta-se a história de um menino em fase de alfabetização e seus conflitos para compreender o significado das palavras. A animação se inicia com a apresentação da palavra "bola" pela professora, com destaque para as dúvidas do menino; mostra, na sequência, o mesmo observando algumas letras no caminho para sua casa; a "Sopa de Letrinhas" preparada por sua mãe e o esforço desta em ensinar-lhe o som das letras; e, a atividade desenvolvida pela professora em sala de aula, momento em que o menino começa a relacionar fonema e grafema, possibilitando a formação e compreensão de novas palavras.

O projeto apresenta a animação Sopa de Letrinhas como um "elemento significativo" para a criança, abordando, na linguagem que lhe é peculiar, os conceitos e conteúdos necessários ao desenvolvimento da linguagem oral e escrita. A escolha das palavras segue a orientação do Serviço de Supervisão Educacional da Secretaria Municipal de Educação, que definiu os fonemas a serem abordados por trimestre, levando em conta o grau de complexidade dos mesmos. No primeiro trimestre, priorizam-se os fonemas que possuem relações regulares, nas quais haja correspondência biunívoca - letras que possuem um único som - independente da posição na palavra, como $b, d, f, p, v, t$ e algumas de relação contextualmente regular, nas quais pode haver alteração no som dependendo da composição da palavra, como $l$, $m, n, r, s$. Além disto, considera-se também o contexto sociocultural dos alunos da Rede. A intenção é facilitar a compreensão e consolidar o conceito de formação de palavras.

A segunda animação prioriza as letras com relações contextualmente regulares, enfatizando como estas podem ter o som modificado, dependendo da posição na palavra. Utiliza-se a mesma letra em posições diferentes e destaca-se a distinção entre os sons. Como na primeira animação, foi considerado o contexto sociocultural do aluno na escolha das palavras.

Objetiva-se utilizar a animação como ponto de partida, possibilitando ao professor o desenvolvimento de atividades dela decorrentes, explorando a temática central e os conceitos abordados. Para tanto, professores alfabetizadores e multiplicadores tecnológicos são estimulados a construir Objetos de Aprendizagem complementares, utilizando o computador, Internet e outras mídias, integrando assim, tecnologia e metodologia. 
Vale ressaltar que o projeto encontra-se em sua fase de implantação, mas já apresenta resultados positivos bastante significativos.

\section{Objetivos}

Foram estabelecidos os seguintes objetivos a serem alcançados no decorrer do projeto:

\section{Objetivo Geral:}

- Integrar Tecnologia e Metodologia, propiciando a professores e alunos de turmas de alfabetização material didático adequado à proposta metodológica da instituição, aos seus interesses e às demandas tecnológicas atuais.

\section{Objetivos Específicos:}

- Utilizar a animação como objeto de aprendizagem, adequando-a à metodologia e à realidade sociocultural dos alunos;

- Estimular o uso pedagógico das mídias disponíveis nas escola;

- Propiciar ao aluno apreender conceitos, princípios e conteúdos, sistematizando-os de forma prazerosa, agregando maior significação ao processo de alfabetização.

\section{Metodologia - descrição dos detalhes do trabalho}

O Projeto Sopa de Letrinhas foi idealizado e implementado pelo Departamento de Formação Continuada da Secretaria Municipal de Educação, mediante iniciativa do Centro de Estudos de Educação Natália Calonazzi e seu Núcleo de Tecnologia Educacional Municipal NTM Cabo Frio, onde o NTM realiza as animações, a equipe de Formação Continuada de Alfabetizadores orienta, acompanha o trabalho desenvolvido pelos professores alfabetizadores da Rede Municipal de Ensino e os professores alfabetizadores e multiplicadores tecnológicos constrem os objetos de aprendizagem.

\section{1 - Das Animações}

As animações são idealizadas tendo como referência a Metodologia Analítica de Alfabetização e as necessidades educacionais apontadas pelos professores alfabetizadores. A temática gira ainda em torno dos conceitos aplicados ao processo de Alfabetização e Letramento. O design foi pensado de forma que houvesse identificação com os desenhos animados que os alunos assistem na TV, foi utilizado o recurso estético da deformação, o traço dos personagens é simples e busca relação com o desenho infantil. Os efeitos sonoros e animações dos personagens, palavras e letras foram planejados de forma a prender a atenção do aluno e solucionar possíveis dúvidas relacionadas aos conceitos apresentados. São usadas cores, tamanhos e animações diferentes em palavras e letras para explicitar conceitos e destacar visualmente detalhes necessários à compreensão.

A primeira animação, denominada "Sopa de Letrinhas", conta a história de Dudu, um menino de seis anos que está aprendendo a ler. Um dia, após a chegada da escola, sua mãe lhe prepara uma sopa de letrinhas. O menino começa, então, a identificar letras e fazer relação com os fonemas. Ao chegar à escola, comenta com a professora sobre a sopa, e a professora usa esse recurso, levando macarrão de letrinhas para a sala de aula, com a finalidade de trabalhar os mecanismos de formação de palavras. Ao final da animação, há o momento da revisão, onde a professora convida o expectador a ler e relembrar os conceitos apresentados no vídeo. Além dos conceitos de formação de 
palavras e o reconhecimento de grafemas relacionando o som de seus respectivos fonemas, são trabalhados os conceitos de vogais e consoantes.

As figuras aqui apresentadas são frames da animação "Sopa de Letrinhas". Cada quadro nomeado entre A e D é um momento da animação, onde ocorrem fatos que chamam a atenção da criança para conceitos que entrarão em cena a seguir.

Pode-se observar na figura 1 - quadro (A), a imagem do personagem Dudu, quando fica confuso durante a apresentação das letras e fonemas pela professora. A intenção aqui é mostrar ao aluno que é comum ter dúvidas durante o processo de aquisição da leitura e da escrita, trabalhando assim a questão da baixa autoestima que muitos alunos sofrem. É uma forma do aluno se ver na figura do personagem e perceber que, se o personagem do desenho animado conseguiu aprender, ele também é capaz.

No quadro (B) da figura 1, Dudu reconhece as letras trabalhadas em sala de aula no seu prato de sopa e em seguida, relaciona algumas delas com seus fonemas. Nota-se o destaque da letra $M$ nessa figura. Nesse momento da animação as letras se destacam em zoom-in enquanto são reconhecidas pelo personagem. Como no processo de letramento os alunos costumam identificar as letras e os fonemas em situações do cotidiano, retratou-se na animação situações comuns, onde o personagem percebe as letras e fonemas em letreiros nas ruas e no prato da sopa de letrinhas preparado pela mãe.

Observa-se, no quadro (C) da figura 1, o momento em que a professora aproveita a situação da sopa, comentada por Dudu, para realizar uma atividade utilizando as letras de macarrão. A mensagem aqui é direcionada ao professor para que perceba a importância de relacionar as atividades e conteúdos com as experiências dos alunos.

Já no quadro (D) da figura 1, mostram-se a classificação das letras em vogais e consoantes, o conceito e o mecanismo de formação de sílabas e palavras.

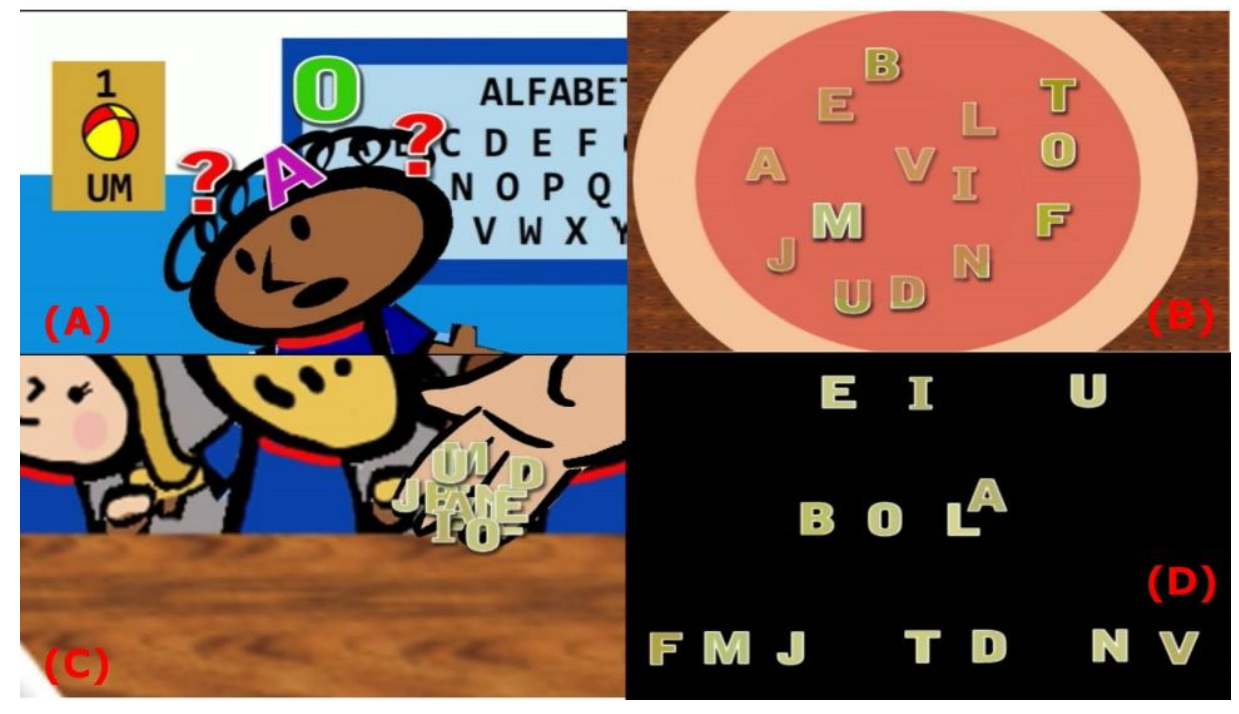

Figura 1. Frames da animação "Sopa de Letrinhas"

Na figura 2 - quadro (A), é atribuído sentido à palavra, pois juntamente com a leitura da mesma, feita pelo personagem, aparece a figura da bola quicando em cada letra, e novamente surge a questão da identificação das letras na palavra, o que é feito através da mudança de cor e não só pelo toque da bola. 
O quadro (B) da figura 2, mostra a dinâmica da formação de novas palavras baseada na substituição de letras. Nesse momento da animação, a letra B, que formava a palavra bola, desliza para fora da tela , no mesmo instante em que a letra $\mathrm{M}$ desliza para dentro e ocupa o lugar da letra $\mathrm{B}$, formando a palavra mola. Esse movimento é narrado pela personagem da professora. Na sequência, Dudu faz a leitura da nova palavra e uma mola quica em baixo de cada letra, enquanto a mesma muda de cor. Mais uma vez se faz presente a questão da identificação das letras na palavra.

No quadro (C) da figura 2, é mostrado o momento da revisão, quando a palavra bolo é formada. As letras $\mathrm{O}$ se destacam uma a uma em tamanho e movimento, chamando a atenção para a hipótese equivocada que alguns alfabetizandos formulam de que não se pode usar uma letra mais de uma vez na mesma palavra. A animação desfaz o equívoco e dá subsídio ao professor para trabalhar a questão com os alunos.

O quadro (D) da figura 2 mostra o momento final, onde a professora fala ao espectador, resumindo o conceito central trabalhado na animação - "Hoje você aprendeu que se trocarmos as letras de uma palavra, formamos palavras diferentes!" - ela termina a fala incentivando o aluno a formar novas palavras.

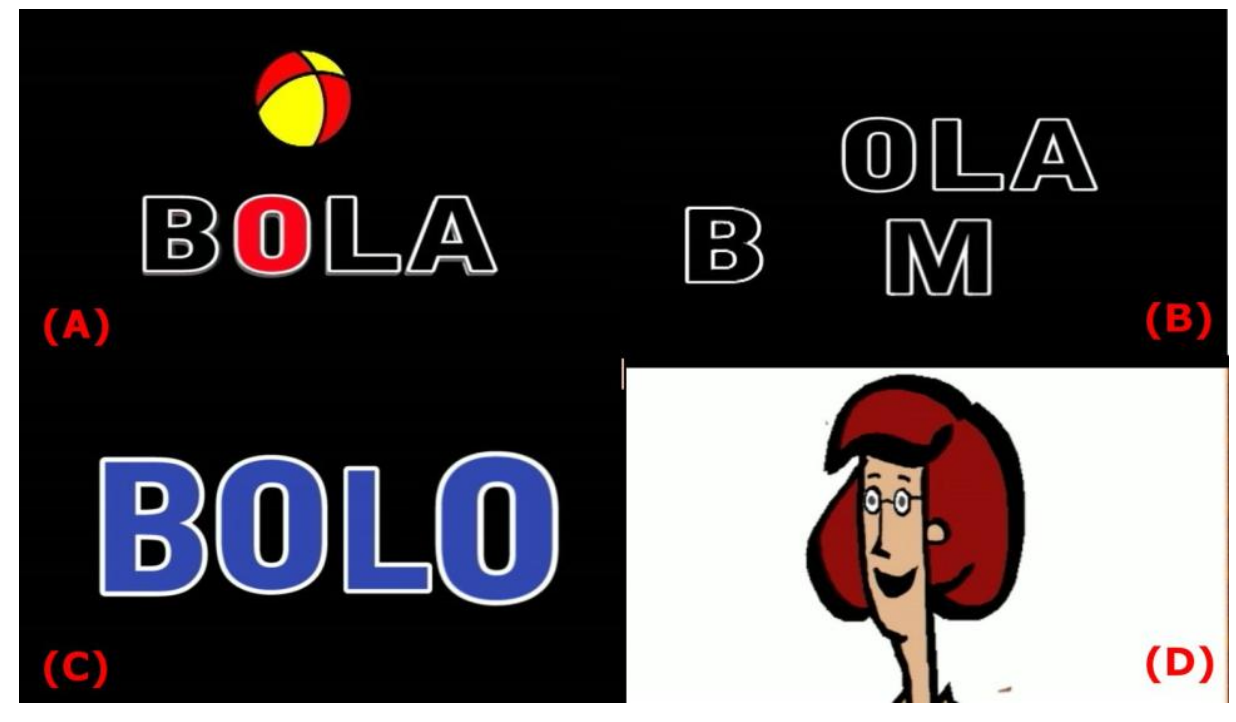

Figura 2. Frames da animação "Sopa de Letrinhas" .

$\mathrm{O}$ roteiro procura usar uma linguagem dialógica, com a finalidade de promover a interatividade com o espectador através da fala do narrador e dos demais personagens. Em momentos estratégicos, estimula-se a leitura das palavras que surgem, inclusive acompanhadas de suas imagens.

A segunda animação, denominada "Sopa de Letrinhas Especial", utiliza todos os recursos estéticos da animação anterior e adiciona um número maior de efeitos sonoros e sequência de movimentos nos objetos apresentados, pois segundo os professores esses recursos muito agradaram aos alunos. A animação também foi feita com uma duração maior, pois os alunos acharam a anterior muito curta. A pedido dos professores, a temática trabalhada nessa segunda animação e também nas vindouras está relacionada às dificuldades da língua, sílabas complexas e formação de frases e textos.

A temática específica da "Sopa de Letrinhas Especial" é o emprego das consoantes pós vocálicas. A animação inicia lembrando aos alunos a situação da história 
apresentada na animação anterior, a Sopa de Letrinhas, e trabalha palavras com sílabas simples através de um bingo, aplicado pela professora, com a finalidade de revisar conteúdos já dominados pela maioria dos alunos da Rede. Ao final da atividade, a professora convida os alunos para acompanhar a confecção de uma sopa de letrinhas especial no refeitório da escola. Na receita dessa sopa, procurou-se adicionar palavras que trabalham as consoantes pós-vocálicas, como ervilhas, carne seca, linguiça, salsa, sal, e hortelã, dentre outras com sílabas simples.

No momento em que a cozinheira cita os ingredientes da sopa, suas figuras caem no caldeirão juntamente com seus nomes correspondentes. As consoantes pós-vocálicas dessas palavras que caem na sopa estão destacadas na cor vermelha, com o objetivo de gerar curiosidade nos espectadores. Ao término do preparo da sopa, os alunos se alimentam e se deparam com a formação de palavras, no seu prato de sopa, que não conseguem ler. Na sala de aula, a professora, ouvindo o burburinho dos alunos, explora a situação e desvenda juntamente com os mesmos o mistério daquelas palavras, trabalhando os conceitos inseridos em cada uma. Ao final, a professora convida o espectador a relembrar os conceitos trabalhados no vídeo. As animações foram disponibizadas em DVD para os professores alfabetizadores e os Multiplicadores Tecnológicos - responsáveis pela dinamização do espaço dos Laboratórios de Informática e postadas no blog Animando a Escola e no site do NTM Cabo Frio.

A figura 03 mostra quatro frames da Animação "Sopa de Letrinha Especial”.

No quadro (A), pode-se observar o momento da confecção da sopa. Nota-se que os alunos estão acompanhando a receita pela janela do refeitório, pois a intenção é não entrar em conflito com as regras estabelecidas pela Rede, que por motivos de higiene e segurança somente os funcionários autorizados podem ter acesso direto à cozinha. Conforme citado acima, os ingredientes são acrescidos à sopa juntamente com suas palavras. A letra L está em destaque para gerar curiosidade nos alunos e criar relação com os conceitos que serão apresentados mais adiante.

O quadro (B) mostra o prato de sopa do aluno Dudu, onde aparece a palavra PASTEL. Nota-se que a cor dessa sopa é verde, isso porque se trata de uma sopa de ervilhas. Nesse momento, chama-se a atenção para o fato de que os alunos não conseguiam ler as palavras, contrapondo à idéia inicial da animação, quando a narradora diz que "depois da sopa de letrinhas, a turma de Dudu já estava lendo tudo". A intenção é mostrar ao espectador que ainda há muito que aprender em relação à leitura e à escrita.

O quadro (C) mostra o momento em que a professora em sala de aula se aproveita da curiosidade dos alunos em relação às palavras estranhas que encontraram na sopa para trabalhar os conceitos contidos nas palavras que possuem consoantes pósvocálicas. A palavra PASTEL, que apareceu na sopa, é comparada à palavra PATÊ, forma como o aluno Dudu a lê. Observa-se que as letras S e L da palavra pastel estão em destaque, com a intenção de identificar as letras que foram ignoradas na leitura do aluno. Na sequência, Dudu mostra que não ignorou as letras, mas que não tinha como ler uma consoante não seguida de uma vogal. A professora desvenda a partir daí o caso de cada palavra encontrada nos pratos de sopa dos alunos: TORTA, MANGA E BOMBOM.

No quadro (D), é mostrado o momento em que a leitura da palavra pastel é feita. Nota-se que a figura que representa o pastel é uma figura real. Optou-se por representar visualmente todas as palavras que aparecem a partir da sopa, numa estética realista por 
se tratar de alimentos que fazem parte do cardápio da criança em casa e na escola. $\mathrm{Na}$ sequência, para agradar o espectador infantil e manter o seu interesse no vídeo, aparece o pastel sendo devorado acompanhado de efeito sonoro que imita a mordida de um alimento crocante, porém sem mostrar o personagem que devora o mesmo.

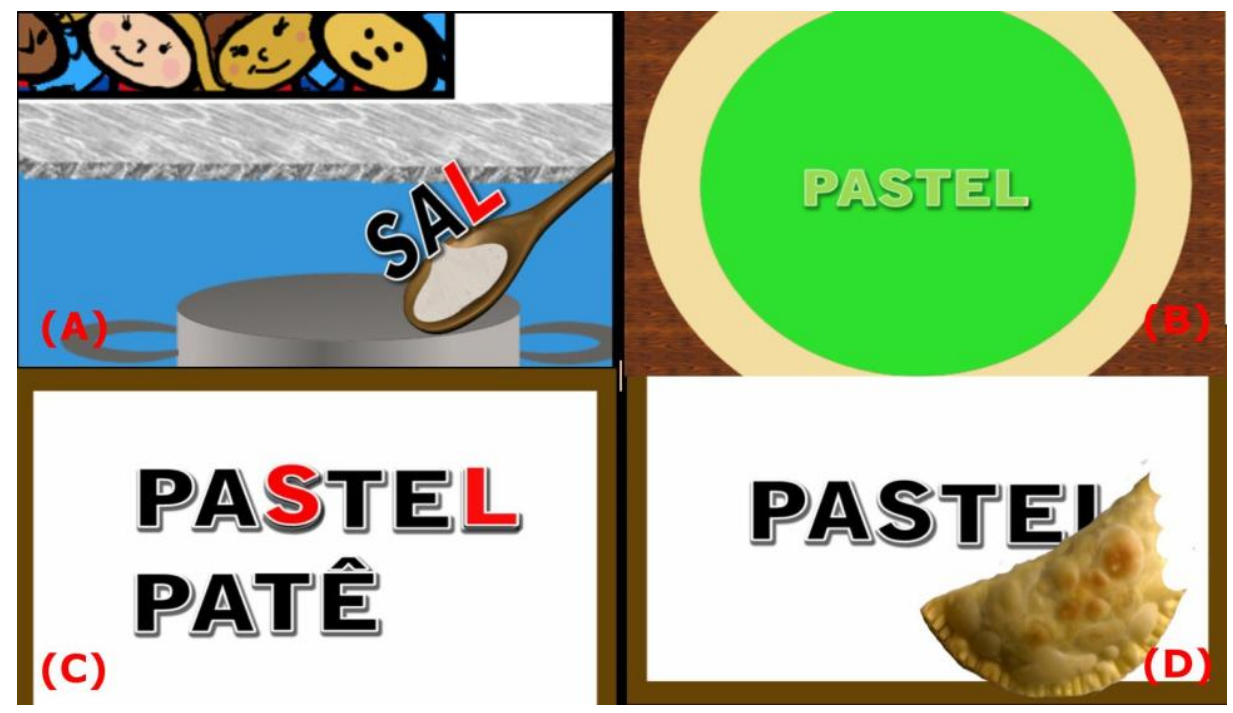

Figura 3. Frames da animação "Sopa de Letrinhas Especial” .

\section{2 - Dos Objetos de Aprendizagem}

“... o aluno, diante da máquina, formula hipóteses, testa-as fazendo experiências práticas (isto é, fornecendo instruções ao computador), obtém respostas, enxerta modificações, avalia novamente a sua eficácia, reformula hipóteses. ” Lollini, 1985

O uso do computador potencializa o processo de construção de conhecimento, por possibilitar ao aluno testar suas hipóteses e reformulá-las. Os objetos de aprendizagem desenvolvidos para o computador vão propiciar uma sistematização de conteúdos muito mais eficaz, por viabilizar o diálogo do aluno com a "máquina", que verdadeiramente se constitui num diálogo com seu próprio cérebro.

Quando fazemos uso da animação como Objeto de Aprendizagem para abordar conceitos, valores, conteúdos e princípios, precisamos sistematizá-los. A sistematização de conteúdos e/ou conceitos na Alfabetização é fundamental na Metodologia Analítica devido à abrangência da mesma. Por partir de um elemento significativo, tal metodologia propicia à criança contato com uma diversidade de informações, que, a menos que sejam sistematizadas adequadamente, não resultam em aprendizagem. $\mathrm{O}$ professor precisa enfocar os conteúdos essenciais àquela fase do processo, desenvolver atividades específicas, que denominamos atividades de sistematização e fazer as intervenções necessárias para que a criança consiga selecionar e armazenar o que é útil. No caso específico da Sopa de Letrinhas, é necessário a complementação dos conteúdos com objetos de aprendizagem, que oportunizem à criança criar suas hipóteses, experimentá-las e, mediante seu erro ou acerto, consolidá-las.

\section{3 - Da orientação dos professores}

"A aprendizagem consiste em uma mudança no comportameno do aluno, em face do processo da instrução, e é o resultado desse processo que, para ser eficiente, precisa ser planejado." Valente, 2001 
Cientes da importância do planejamento, os professores assistiram em grupo à Sopa de Letrinhas e identificaram os princípios, conceitos e conteúdos nela inseridos. Relacionaram os conteúdos já abordados em suas turmas, identificaram as principais dificuldades e listaram as possibilidades da sistematização propiciadas pela animação. Foram orientados a elaborar um planejamento com objetivos bem definidos, tendo a animação "Sopa de Letrinhas" como objeto de aprendizagem principal, seguida de atividades de sistematização específicas para suas turmas. Tais atividades foram criadas por cada professor, considerando a necessidade da turma como um todo e de alguns alunos em particular. Após o desenvolvimento da aula, os professores compartilharam a experiência, apontando os acertos, erros, dificuldades, resultados e apresentaram também sugestões para o roteiro das próximas edições da Sopa de Letrinhas.

\section{Alguns Relatos}

Conforme citado anteriormente, a segunda animação, Sopa de Letrinhas Especial, sofreu adequações baseadas no retorno de alunos e professores, dentre os quais destacamos os seguintes relatos:

Professora 1, que testou a animação com um sobrinho que se encontra em processo de alfabetização: "Meu sobrinho vibrou e interagiu o tempo todo, principalmente nos momentos de leitura. Quando a animação terminou, perguntei por que ele leu. Ele respondeu: porque a professora mandou."

Professora 2, que utilizou a animação com sua turma: "Os alunos prestaram atenção na animação e leram juntamente com o personagem e também no final, no momento da revisão. Ficaram admirados com o movimento e barulho da bola, da mola e do bolo - todos imitaram. Ao saberem que a animação havia sido feita para eles, ficaram orgulhosos e falaram para outros alunos da escola com bastante entusiasmo."

Professora 3, que após a exibição da animação para sua turma, elaborou uma atividade inspirada na mesma: "Trabalho na zona rural do município e descobri que meus alunos não conheciam macarrão de letrinhas, então eu procurei no supermercado, e levei para a sala de aula junto com pratinhos de papelão, onde escrevi SOPA DE LETRINHAS e disse aos alunos que iríamos fazer a atividade que apareceu na animação, então eu ditava palavras com os fonemas da animação e os alunos procuravam as letras de macarrão e montavam-nas. Eles adoraram."

Professora 4, que relatou um importante avanço de um aluno durante a animação: "Ele tinha muita dificuldade, não conseguia ler nada, mas durante a animação observei que ele acompanhava a leitura, depois da animação fiz uma sondagem de forma discreta e constatei que ele havia entendido o mecanismo de formação de palavras, pois continuava a ler."

Professora 5, que está abordando o tema animais com sua turma: "Foi a primeira vez que planejei e desenvolvi uma atividade no laboratório de informática educativa. Primeiro assistimos à animação: os alunos interagiram o tempo todo, liam as palavras e respondiam à professora da animação. Conversamos sobre a mesma e revisamos as sílabas já estudadas, a partir das palavras da animação. Em seguida abordamos o nosso tema, animais, utilizando o datashow para projeção de imagens. Espalhei letras móveis sobre a mesa e solicitei que cada aluno formasse o nome do animal que era projetado na tela. Os alunos interagiam entre si e formavam as palavras. Na sala de aula, os alunos fizeram uma lista com todas as palavras formadas. 
Para mim, foi uma experiência maravilhosa, vi a minha turma motivada e aprendendo com prazer."

Aluno 1, referindo-se ao dia de aula no qual a professora utilizou a animação: "Tia, a aula hoje foi muito legal! Amanhã vai ter de novo?"

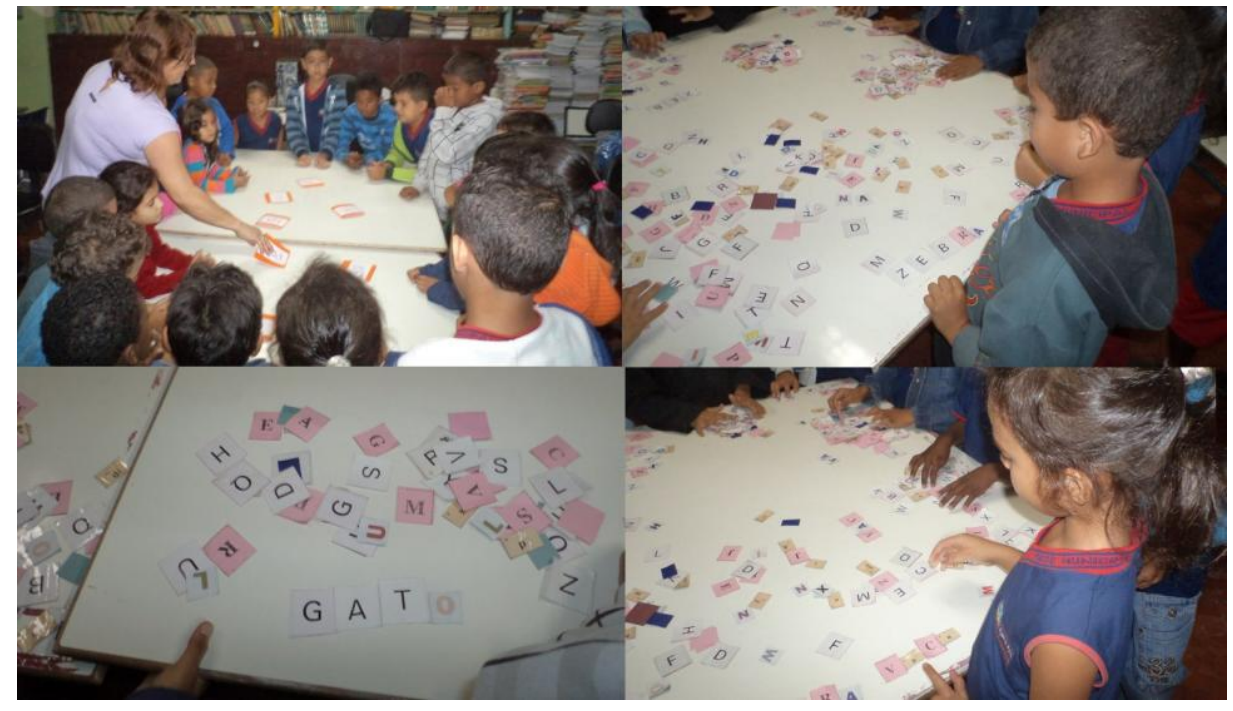

Figura 4. Atividades desenvolvidas pela Professora 5 com seus alunos.

\section{Considerações Finais}

O projeto está sendo implantado em turmas de Alfabetização e em alguns laboratórios de informática para crianças com dificuldades na aprendizagem da leitura e da escrita. Os alunos estão recebendo-o com curiosidade e entusiasmo, pois identificam-se com as situações citadas e interagem com personagens e narrador. Além disso, relacionam os conceitos e conteúdos abordados com suas vivências e, em alguns casos, começam a compreender conceitos ainda não sistematizados. O prazer na aprendizagem é evidenciado nos relatos de alunos e professores, que também estão vivendo uma experiência nova com animação em sala de aula - desenvolvida especialmente para eles. Esse resgate do prazer em aprender, por si só, já justificaria todo o projeto. No entanto, percebemos avanços significativos também na aprendizagem.

Além dos resultados da animação em si, estimulamos os professores a criarem outros objetos de aprendizagem, que complementam a sistematização dos conceitos, voltados para as necessidades educacionais específicas de cada turma. Sendo assim, uma mesma animação adequa-se a contextos diferenciados, propiciando uma variedade de objetos de aprendizagem, que compartilhados podem favorecer o desenvolvimento da Rede Municipal de Ensino como um todo.

Considerando-se os resultados dessa fase inicial de implantação, os relatos positivos de professores e alunos frente ao uso dessa tecnologia, pode-se dizer que a animação em estudo, além de seu inegável poder motivacional, contribui para uma melhor compreensão de conceitos e conteúdos, revelando-se importante ferramenta também na aprendizagem da leitura e da escrita dos alunos das turmas de alfabetização da era digital. 


\section{Referências}

SEME - Secretaria Municipal de Educação de Cabo Frio, REDEALFA, Referencial de Alfabetização. Rio de Janeiro, 2006.

MORAIS, Artur G., ALBUQUERQUE, Eliana B. C. \& LEAL, Telma F. (orgs). Alfabetização: apropriação do sistema de escrita alfabética. Belo Horizonte, Autêntica, 2005.

STAMPA, Mariângela. Aquisição da Leitura e da Escrita: uma abordagem teórica e prática a partir da Consciência Fonológica. Rio de Janeiro, Wak Ed., 2009.

VALENTE, Nelson. Didática: Aprendizagem: recursos audiovisuais. São Paulo, Panorama, 2001.

LOLLINI, Paolo. Didática \& Computador: quando e como a informática na escola. São Paulo, Loyola, 1991.

Oliveira, R. de. (2000), “Informática Educativa”. $4^{\mathrm{a}}$ ed. Campinas: Papirus

MATHIAS, Carlos, GIESTA, Alícia, Objetos de Aprendizagem. Novas Tecnologias no Ensino da Matemática. Informática no Ensino da Matemática II

Acesso em: 10/08/2012

http://www.slideshare.net/aldojosecamargo/objetos-de-aprendizagem

Acesso em: 25/09/2012

http://animandoaescolantmcf.blogspot.com

Acesso em: 26/09/2012

http://ntmcabofrio.webnode.com.br

Acesso em: 26/09/2012

http://www.slideshare.net/ReginaCliaSantos/mt-integrando-tecnologia-e-metodologia

Acesso em: 26/09/2012 